provided by how the injury was caused. Often a trip against or on to a blunt object produces a part crushing, part shearing action against the subcutaneous bony edge of the tibia. This tears a flap and damages the local circulation, reducing the viability of the apex of the flap and predisposing to oedema and formation of a haematoma.

So the casualty officer should beware a curled up, paper thin, dusky looking but relatively small wound in this site; but if he is busy all too often he is tempted to suture the flap into place, apply a crepe bandage, and arrange for the patient to return in 10 days. At the second visit inspection of the wound will show that the apex and much of the suture line are non-viable-the result of suturing under tension. Thereafter the patient needs six to ten weeks or more of frequent dressings before the wound heals by granulation. Various attempts have been made to achieve a more rapid or less disturbed healing time; these have included suturing down one side of the $\mathrm{V}$ flap and applying small islands of split skin to the gap on the other, and excising the area with primary grafting and bed rest. ${ }^{1}$ Using this second technique, Tandon and Sutherland ${ }^{2}$ reduced the length of their patients' hospital stay from an average of 60 to 35 days, but even the latter represents a major disruption of the patient's life and a considerable expense to the hospital service.

In a recently described conservative approach ${ }^{3}$ the primary treatment is confined to minimal trimming of avascular margins, tags, and loose fat, and applying adhesive skin sutures to stop the flap curling up-avoiding any tension. A layer of unmedicated tulle gras is then laid over the open wound area and a Viscopaste bandage applied from toes to below knee. This avoids the need for a frequent change of dressing and provides support to an area prone to oedema. The Viscopaste is changed every fortnight in outpatients until the wound is healed, and then the patient can start walking again. In a series of 48 patients treated in this way the average healing time was 65 days with some resolving in as few as 41 days. The benefits of the approach include a relatively simple and rapid initial procedure, avoidance of patient disturbance and cost of admission, and a significant reduction in the number of outpatient visits-a gain to the patient, the hospital, and the district nursing and ambulance services.

\footnotetext{
1 Woodyard, J E, Practitioner, 1968, 200, 533.

2 Tandon, S N, and Sutherland, A B, British fournal of Plastic Surgery, $1973,26,172$.

${ }^{3}$ Crawford, B S, and Gipson, M, British Fournal of Plastic Surgery, 1977, 30, 174.
}

\section{Anorexia nervosa: fear of fatness or femininity?}

Characterised by a wilful and successful refusal to eat associated with a preoccupation with food and weight loss-and amenorrhoea in those teenage girls who form the bulk of the patients-anorexia nervosa continues to fascinate both classifiers and theorists. Though the idea is out of favour, the disorder could still be due to a primary hypothalamic disturbance, ${ }^{12}$ for hypothalamic tumours may give rise to a distaste for food. The abnormal behaviour seen in anorexia nervosa ${ }^{3-6}$ may not be confined to the patients, but may also be seen in the parents ${ }^{5}$; and the affective changes in family members have led a group at the University of California ${ }^{7}$ to restate the proposition that some cases are atypical affective disorders, modified by the psychological attributes of female adolescence. The near-delusional preoccupation of patients with anorexia nervosa with body image suggests an overlap with the dysmorphophobias, which have a similar age and social class incidence and also occur in obsessional, dysthymic personalities who are excessively concerned with achieving perfection. ${ }^{8}$

Among the psychological theories of causation Dally ${ }^{9}$ has mentioned the idea that the patient may be a scapegoat chosen by the family. Nevertheless, he is more concerned that the family, particularly the mother, may often be chosen as a scapegoat (by the patient or the doctor, or both) to take the blame for the anorexia nervosa. Three-quarters of the mothers of his patients had depression, and he emphasised the need to support and treat them. The original psychodynamic formulation $^{10}$ of anorexia nervosa related the refusal of food to fantasies about impregnation through oral sexual relations. Crisp.11 12 sees food as representing not the male sex but the patient's own developing femininity, and her aversion to carbohydrate is, he believes, an aversion to the building blocks of her own breasts and hips, which suggest to her that she is being fattened up for the marriage market. For this reason she refuses to turn into a woman and by dieting she maintains her body mass below the level which is thought to trigger puberty. Might this theory derive some support from the finding that anorexia is common among middle-class schoolgirls but rare in working-class ones?

A contrary view ${ }^{13}$ has been taken by some Chicago workers, who believe that the syndrome starts as normal dieting with the aim of increasing the girl's sexual attractiveness but that for some reason the dieting gets out of control. This theory, too, is compatible with the preponderance of patients from the middle class, a group not renowned for setting limits on the urge to self-improvement: for the father no bank balance is large enough, for the mother no carpet is clean enough, for the daughter no dimensions are small enough.

Perhaps the nature of these dimensions might help us to choose between the two theories-the girl who fears femininity should be concerned about her breasts and hips, whereas one who fears fatness should be more preoccupied with her waist. Anorexic girls have long been known to regard their shape as more normal than it is and to overestimate their dimensions. The results of recent work, ${ }^{14}$ while far from conclusive, suggest that it is the stomach and not the bust which is subjected to distorted perception. May we also apply these findings to obesity ? If anorexia nervosa is a phobia of femininity or of fatness, how many patients with obesity have phobias of asexuality or of thinness?

${ }^{1}$ Russell, G, Psychological Medicine, 1977, 7, 363.

2 Lupton, N, et al, Life Sciences, 1976, 18, 1341.

${ }^{3}$ Swann, I, Practitioner, 1977, 218, 424.

4 White, G H, Kelly, P, and Dorman, K, American fournal of Psychiatry, $1977,134,323$.

${ }^{5}$ Heron, G B, and Johnston, B A, American fournal of Psychiatry, 1976, 133, 580 .

6 Lewin, K, Mattingly, D, and Millis, R R, British Medical fournal, 1972, $2,629$.

7 Cantwell, D T, et al, Archives of General Psychiatry, 1977, 34, 1087.

${ }^{8}$ Andreasen, N C, and Bardach, J, American fournal of Psychiatry, 1977, 134, 673.

9 Dally, P, Proceedings of the Royal Society of Medicine, 1977, 70, 470.

10 Waller, J V, Kaufman, M R, and Deutsch, F, Psychosomatic Medicine, $1940,2,3$.

11 Crisp, A H, Proceedings of the Royal Society of Medicine, 1977, 70, 464.

12 Crisp, A H, Palmer, R L, and Kalucy, R S, British fournal of Psychiatry, 1976, 128, 549

${ }^{13}$ Casper, R C, and Davis, J M, American fournal of Psychiatry, 1977, 134, 974.

14 Button, E J, Fransella, F, and Slade, P D, Psychological Medicine, 1977, 7, 235. 